\title{
THE VALIDITY AND RELIABILITY OF THE SUMMARY OF DIABETES SELF- CARE ACTIVITIES QUESTIONNAIRE: AN INDONESIAN VERSION
}

\author{
Sugiharto, RN., Ph.D. ${ }^{1 *}$, Yu-Yun Hsu, RN., Ph.D ${ }^{2}$, Deborah J. Toobert, Ph.D ${ }^{3}$, Shan-Tair Wang, \\ Ph. $\mathrm{D}^{4}$ \\ ${ }^{1}$ University of Muhammadiyah Pekajangan Pekalongan, ${ }^{2}$ National Cheng Kung University, Taiwan, ${ }^{3}$ \\ Oregon Research Institute, 1776 Millrace Drive Eugene, Oregon 97403, ${ }^{4}$ National Cheng Kung \\ University, Taiwan \\ Email*: sugiharto76@stikesmuh-pkj.ac.id/gie_soma@yahoo.co.id
}

\begin{abstract}
Introduction: Diabetes self-care activities is a complex regimen, that required an appropriate tools to asses. The Summary of Diabetes Self-Care Activities (SDSCA) questionnaire is the most widely used tool for assess diabetes self-care activities. The study aimed to testing validity and reliability of the Bahasa Indonesia version of the SDSCA. Methods: The study applied a forward-backward translation strategy. A pretest and a validation study were conducted. The Bahasa Indonesia version of the SDSCA was reviewed by an expert panel for conceptual and content equivalence to the English version. Furthermore, forty-five and 125 patients with T2DM participated in the pretest and the validation study, respectively. The psychometric properties were evaluated in terms of internal consistency, content validity, concurrent validity, and construct validity. Results: The content validity index (CVI) and the internal consistency (Cronbach's alpha) were satisfactory, which are 0.98, and 0.72, respectively. The exploratory factor analysis revealed that SDSCA-I are consistent with the original English version. There are significant correlations between three subscales of SDSCA-I and the diabetes knowledge levels namely general diet $(r=0.274, p=0.002)$, physical activity $(r=0.269, p=0.002)$, and foot care $(r=0.297, p=$ $0.001)$. SDSCA-I was significantly correlated with HbAlc values, in term of general diet $(r=-0.205, p=0.022)$ and self-monitoring of blood glucose $(r=-0.265, p=0.003)$. Conclusions: The translation and psychometric test of the SDSCA-I were satisfactory. The tool could assess the self-care activities of Indonesians with T2DM in all settings.
\end{abstract}

Keywords: diabetes self-care activities questionnaire; forward-backward translation; psychometric properties; type 2 diabetes mellitus (T2DM)

\section{INTRODUCTION}

The global prevalence of diabetes mellitus (DM) has been predicted to increase from 415 million in 2015 to 642 million in 2040 (International Diabetes Federation [IDF], 2015). Indonesia ranks second in the prevalence of DM in the Southeast Asia Region (World Health Organization, 2016), with approximately ten million sufferers (IDF, 2015). The majority of these patients have type 2 diabetes mellitus (T2DM) (National Institute of Research and Development of Health, 2013). Evidence shows that T2DM threatens DMrelated complications, such as macro- and micro-vascular complications, whose rates are $27.2 \%$ and $53.5 \%$, respectively (Litwak et al., 2013). In Indonesia, the mortality rate due to
DM complications is $74.3 \%$ (National Institute of Research and Development of Health, 2013). Theoretically, these complications can be prevented by modifying lifestyle (Weber, OzaFrank, Staimez, Ali, \& Venkat Narayan, 2012) and implementing self-care activities (American Diabetes Association [ADA], 2018).

Diabetes self-care activities are an essential strategy that can prevent or delay diabetes complications by maintaining ideal glycemic control (ADA, 2018; Coyle, Francis, $\&$ Chapman, 2013). Seven regimens of diabetes self-care activities have been recommended, namely healthy eating, being active, monitoring, taking medications, problemsolving, healthy coping, and reducing risks (American Association of Diabetes Educator, 
2014). A study showed that self-care activities can improve $\mathrm{HbA} 1 \mathrm{c}$ by $0.36 \%$ milligrams per deciliter (Minet, Møller, Vach, Wagner, \& Henriksen, 2010). Empirically, the adherence rate of self-care in developing countries is low (Dal Santo Francisco Bonamichi et al., 2016). In line with this, in most Asian countries, the goal of self-care activities was unachievable (Ramachandran, Snehalatha, Shetty, \& Nanditha, 2012).

A possible reason for the low adherence to self-care activities is the complexity of the regimens. Moreover, the assessment of self-care performance is important for monitoring and determining selfcare support. Several diabetes self-care assessment tools have been developed with good psychometrics, but most are in the English language. The Summary of Diabetes Self-Care Activities (SDSCA), developed by Toobert and Glasgow, is the most widely used tool for assessing diabetes self-care activities (Toobert \& Glasgow, 1994). SDSCA revised version contains 25 items related to diet, medication, foot care, physical activity, self-monitoring of blood glucose, smoking, and self-care recommendations from healthcare providers (Toobert, Hampson, \& Glasgow, 2000). SDSCA has been recognized as a simple, valid, and reliable questionnaire (Adarmouch, Sebbani, Elyacoubi, \& Amine, 2016; Toobert et al., 2000). It has thus been translated into several languages, including Chinese $(\mathrm{Xu}$, Savage, Toobert, Pan, \& Whitmer, 2008), Spanish (Vincent, McEwen, \& Pasvogel, 2008), Turkish (Kav et al., 2010), Korean (Choi et al., 2011), Malay (Jalaludin, Fuziah, Hong, Adam, \& Jamaiyah, 2012), German (Kamradt et al., 2014), Arabic (AlJohani, Kendall, \& Snider, 2014), and Moroccan (Adarmouch et al., 2016). The above studies have confirmed that SDSCA is a valid and reliable scale for assessing diabetes self-care activities for DM patients across cultural backgrounds.

Since Indonesia has a high prevalence of DM, the Indonesian National Health Insurance recently provided a program namely PROLANIS, for patients with T2DM to increase their knowledge and self-care activities related to DM. However, there is a lack of a valid tool for assessing diabetes selfcare activities. Therefore, the present study aimed to translate SDSCA into the Indonesian language and examine its psychometric properties.

\section{METHODS}

\section{Study design}

The SDSCA questionnaire was translated using a forward-backward translation approach. There are six stages in the forwardbackward translation process: translation, synthesis, back translation, expert committee review, pretesting, and submission and appraisal (Beaton, Bombardier, Guillemin, \& Ferraz, 2000). A cross-sectional design was applied to evaluate the psychometric properties of the SDSCA.

\section{Setting and Participants}

Two groups of participants were recruited for this study. The first group was recruited for a pretest, which was conducted to assess the readability and clarity of the Indonesian version of SDSCA (SDSCA-I). The participants in the first group were recruited from "Ngesti Waluyo" diabetes club Parakan, Central Java. The participants of the second group were recruited from community health centers in Pekalongan, Central Java, to test the psychometric properties of SDSCA-I. The inclusion criteria of the participants were $\geq 18$ years of age, literate in Bahasa Indonesia, and diagnosed with T2DM. The exclusion criteria included T2DM patients with physical or psychological limitations for conducting selfcare, serious diabetes complications (e.g., renal failure, acute myocardial infarction, or stroke), and severe psychiatric disorders. This study was conducted from October 2014 to October 2015.

\section{Measurements}

There are tree variables were measured included self-care activities, diabetes knowledge, and HbA1c. The self-care activities was assessed using the summary of diabetes 
self-care activities questionnaire. Diabetes knowledge questionnaire was used to evaluate the knowledge level of diabetes among the participants. And HbAlc was analyzed using clover A1c mechine. Detail of these tree measurements are described below.

\section{The Summary of Diabetes Self-Care}

\section{Activities Questionnaire}

SDSCA is a self-reported questionnaire that assesses the frequency of performing diabetes self-care in the preceding 7 days. The original SDSCA questionnaire consists of 25 items that distributed in the diabetes regimen namely general diet, specific diet, exercise, blood-glucose testing, foot care, medication, and smoking (Toobert et al., 2000). The respondents score their adherence to the selfcare activities within the past week, ranging from 0 to 7 days. The SDSCA has been proven to have good psychometric properties, with acceptable inter-item correlation $($ mean $=0.47)$, moderate test-retest correlations (mean $=0.40$ ), and low correlations among the five dimensions (mean $r=0.23$ ) (Toobert et al., 2000).

\section{Diabetes Knowledge Questionnaire}

The Diabetes Knowledge Questionnaire (DKQ) is a self-report scale for assessing one's knowledge of diabetes (Eigenmann, Skinner, \& Colagiuri, 2011). There are 14 multiple-choice questions with the following scoring system: $0=$ incorrect, $1=$ correct, and $0.5=$ unsure. The internal consistency of DKQ has been proven, with a Cronbach's alpha of 0.76 (Eigenmann et al., 2011). DKQ was applied to assess the concurrent validity of SDSCA because knowledge of diabetes is coincident with selfcare performance (Kueh, Morris, \& Ismail, 2017).

\section{$\underline{H b A 1 c}$}

The HbA1c level of the participants was measured to serve as an indicator of assessing concurrent validity. In this study, $\mathrm{HbA1c}$ levels were measured using an analyze machine with a drop of capillary whole blood. The blood sample was drawn after the participants had completed SDSCA-I.

\section{Research procedures}

\section{Translation procedures}

Permission to translate SDSCA was obtained from its creator (Dr. Toobert). Approval for the study was obtained from the Ethical Committee at the Universitas Muhammadiyah Yogyakarta (407/EP-FKIKUMY/IX/2015).

The SDSCA questionnaire was translated using a forward-backward translation model (Figure 1). The English version of SDSCA was translated into Bahasa Indonesia independently by two bilingual nurses. Then, the two translators met to synthesize the results and reach a consensus. The Indonesian version of SDSCA was translated back into an English version by a bilingual nurse and an English translator, independently. Finally, the Indonesian version of SDSCA was approved by an English language center in Indonesia; both versions attained a linguistic consensus.

Nine healthcare professionals, including physicians, dietitians, pharmacists, diabetes educator nurses, and clinical nurses, participated in evaluating the content of SDSCA-I related to diabetes care concepts, culture, and linguistic context. The content evaluation was used a 1-4 scoring system $(1=$ not relevant to $4=$ highly relevant). Qualitative comments were also collected.

Figure 1. Translation Process

Stage 1:

Two initial translation $(\mathrm{T} 1 \& \mathrm{~T} 2)$ into

Bahasa Indonesia

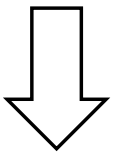

Stage 2:

Synthesize T1 \& T2 into T12, gain

consensus

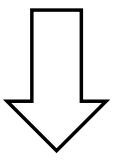

Stage 3:

Back-translation from T12 into BT1 \& BT2 


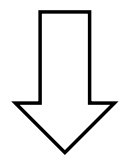

Stage 4:

Nine (9) expert committee review, produce pre-final version

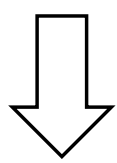

\section{Stage 5:}

Pretesting/pilot study of the pre-final version

$45 \mathrm{~T} 2 \mathrm{DM}$ patients

\section{Study procedures for pretest and SDSCA-I validation}

Two waves of the study were implemented. In the first wave, a pretest was conducted to assess the clarity and readability of SDSCA-I. Forty-five patients with T2DM were invited to fill out the SDSCA-I questionnaire and were interviewed regarding its content. According to Beaton et al. (2000), 30-40 respondents are recommended in the pretesting stage. In the second wave, 125 participants with T2DM were recruited for evaluating the psychometric properties of SDSCA-I. Because SDSCA is a wellestablished questionnaire, the sample size in this study was acceptable and it could yield a reliable result (Mundfrom, Shaw, \& Ke, 2005; de Winter, Dodou, \& Wieringa, 2009). Participants signed informed consent forms prior to enrolling in the study. They filled out the 25-item SDSCA-I and DKQ questionnaires. Subsequently, blood samples were drawn from the participants to examine their $\mathrm{HbA1c}$ levels.

\section{Data analysis}

The content validity of SDSCA-I was analyzed using the content validity index (CVI) with a 4-point scoring system (from $1=$ not relevant to $4=$ highly relevant). Furthermore, the rating was dichotomized into "relevant" (scores of 3 or 4) and "not relevant" (scores of
1 or 2). The item-CVI (I-CVI) was computed as the number of experts giving a rating of relevant, divided by the total number of experts. I-CVI was reflected by an inter-rater agreement that a score of 0.78 is regarded as good (Pilot \& Beck, 2006). The score-CVI (S-CVI) was calculated as the average proportion of items rated as relevant by the experts. There are no criteria for S-CVI (Polit and Beck, 2006). Item analysis was used to examine the homogeneity of the items in the SDSCA-I. Cronbach's alpha was computed to examine the internal consistency of SDSCA-I. Exploratory factor analysis (EFA) with principal component analysis and varimax rotation was applied to determine the factor structures of SDSCA-I, and the absolute value was set of above 0.40 . Pearson's correlation was used to examine the concurrent validity between SDSCA-I and DKQ and between SDSCA-I and HbA1c levels.

\section{RESULTS}

\section{Characteristics of participants}

The pretest (Wave I) included 45 participants and the validation study (Wave II) included 125 participants. The demographic characteristics of the two groups are shown in Table 1. The average age of the participants in Wave I was 55.24 years (standard deviation $[\mathrm{SD}]=8.27$ years) and that in Wave II was 55.10 years ( $\mathrm{SD}=7.12$ years). The average duration of diabetes from diagnosis was 5.77 years $(\mathrm{SD}=5.16$ years) in Wave I and 4.85 years $(\mathrm{SD}=5.14$ years) in Wave II. The majority of participants in both groups were female and had a low level of education. The majority of participants (> 82\%) were being treated with an oral hypoglycemic agent. Just over half of the participants had never received any diabetes education (51.2\%). Based on the participants' report in Wave II, almost twothirds (73.6\%) had no DM complications. More than half (64.8\%) in Wave II had a low level of income. 
Table 1. Characteristics of Participants

\begin{tabular}{|c|c|c|}
\hline Characteristic & $\begin{array}{c}\text { Sample Wave } I(n=45) \\
\text { mean }(S D)\end{array}$ & $\begin{array}{c}\text { Sample Wave II }(\mathrm{n}= \\
125) \\
\text { mean }(S D)\end{array}$ \\
\hline Age & $55.2(8.3)$ & $55.1(7.1)$ \\
\hline \multirow[t]{2}{*}{ Year of diagnosed DM } & $5.8(5.2)$ & $4.9(5.1)$ \\
\hline & $n(\%)$ & $n(\%)$ \\
\hline \multicolumn{3}{|l|}{ HbA1c } \\
\hline$<7 \%$ & - & $0(0 \%$ \\
\hline$\geq 7 \%$ & & $125(100 \%)$ \\
\hline \multicolumn{3}{|l|}{ Gender } \\
\hline Male & $17(37.8)$ & $41(32.8)$ \\
\hline Female & $28(62.2)$ & $84(67.2)$ \\
\hline \multicolumn{3}{|l|}{ Education levels } \\
\hline No formal education & - & $39(31.2)$ \\
\hline Elementary & $20(44.4)$ & $38(30.4)$ \\
\hline Senior High School & $16(35.6)$ & $32(25.6)$ \\
\hline Higher Education & $9(20)$ & $16(12.8)$ \\
\hline \multicolumn{3}{|l|}{ Treatment regimen } \\
\hline No treatment & $8(17.8)$ & $17(13.6)$ \\
\hline $\mathrm{OHA}^{*}$ & $37(82.2)$ & $104(83.2)$ \\
\hline Insulin & - & $1(0.8)$ \\
\hline $\mathrm{OHA}+$ insulin & - & $3(2.4)$ \\
\hline \multicolumn{3}{|l|}{ Diabetes education received } \\
\hline Yes & $30(66.7)$ & $61(48.8)$ \\
\hline No & $15(33.3)$ & $64(51.2)$ \\
\hline \multicolumn{3}{|c|}{ Complication by participants' report } \\
\hline No complication & & $92(73.6)$ \\
\hline 1 complication & & $30(24.0)$ \\
\hline 2 complication & & $3(2.4)$ \\
\hline \multicolumn{3}{|l|}{ National Health Insurance } \\
\hline Yes & & $91(72.8)$ \\
\hline No & & $34(27.2)$ \\
\hline \multicolumn{3}{|l|}{ Income (million Rupiahs) } \\
\hline$<2$ & & $81(64.8)$ \\
\hline $2-4$ & & $32(25.6)$ \\
\hline$\geq 4$ & & $12(9.6)$ \\
\hline
\end{tabular}

* OH A - Orol Hvmorlvamis A somts

Content validity and participants' feedback

The I-CVI and S-CVI of SDSCA-I were 0.99 and 0.88 , respectively. In addition, the experts suggested adding examples for Item 4 (i.e., high-fat foods such as red meat or fullfat dairy products) and Item 5A (i.e., space carbohydrates evenly throughout the day). In the pretest, the qualitative feedback from the participants was also collected. The participants had difficulty understanding of meanings of Items 3 and 5. "servings" of fruit and vegetables and "exact serving amount" of carbohydrates were difficult to understand for the participants. The participants also suggested that items with similar regimens be grouped into one subscale, which would aid the answering of questions. 
Table 2. The item analysis and reliability of the SDSCA-I (Continue)

\begin{tabular}{|c|c|c|c|c|c|}
\hline $\begin{array}{l}\text { 12. Wash the } \\
\text { feet } \\
\text { properly }\end{array}$ & $\begin{array}{l}1.04 \pm \\
2.28\end{array}$ & 0.542 & 0.677 & 0.569 & 0.682 \\
\hline $\begin{array}{l}\text { 13. Soak the } \\
\text { feet }\end{array}$ & $\begin{array}{l}6.36 \pm \\
1.58\end{array}$ & -0.523 & 0.759 & -0.537 & 0.776 \\
\hline $\begin{array}{l}\text { 14. Dry } \\
\text { between } \\
\text { toes after } \\
\text { washing }\end{array}$ & $\begin{array}{l}1.13 \pm \\
2.35\end{array}$ & 0.518 & 0.679 & 0.525 & 0.687 \\
\hline Medication & & & 0.48 & & 0.48 \\
\hline $\begin{array}{l}\text { 15. Take } \\
\text { diabetes } \\
\text { medication }\end{array}$ & $\begin{array}{l}3.96 \pm \\
3.10\end{array}$ & 0.349 & 0.700 & 0.324 & 0.713 \\
\hline $\begin{array}{l}\text { 16. Insulin } \\
\text { injection }\end{array}$ & $\begin{array}{l}0.25 \pm \\
1.18\end{array}$ & 0.401 & 0.701 & 0.351 & 0.714 \\
\hline $\begin{array}{l}\text { 17. Take } \\
\text { number of } \\
\text { diabetes } \\
\text { pills }\end{array}$ & $\begin{array}{l}3.81 \pm \\
3.08\end{array}$ & 0.402 & 0.692 & 0.405 & 0.703 \\
\hline \multicolumn{6}{|l|}{ Smoking } \\
\hline $\begin{array}{l}\text { 18. Are you } \\
\text { smoker }\end{array}$ & $\begin{array}{l}0.10 \pm \\
0.30\end{array}$ & -0.286 & 0.722 & - & - \\
\hline
\end{tabular}

SDSCA-I: the Summary of Diabetes Self-Care Activities-Indonesian version; ${ }^{\text {a}}$ : crude analysis of 18 items; ${ }^{b}$ : analysis if item $3,4,5$, and 18 were deleted

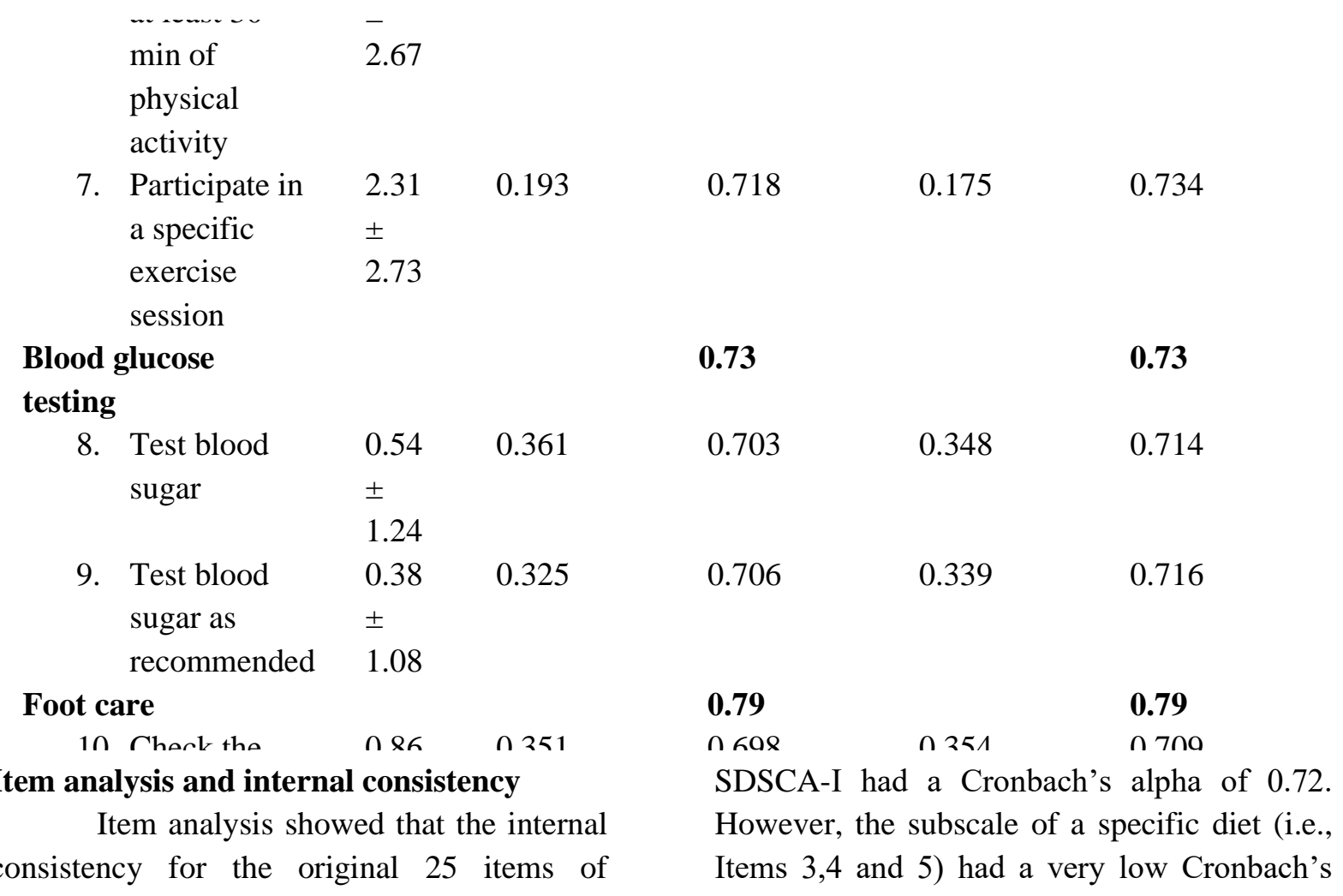


alpha of 0.07. The results of item-deleted Cronbach's alpha indicated that when Items 3, 4 , and 5 were deleted, the internal consistency of SDSCA-I did not increase significantly (0.73). Accordingly, we decided to retain Items 3,4 , and 5. The final version of SDSCA-I has a Cronbach's alpha of 0.72 ; the highest Cronbach's alpha (0.88) is for the subscale of physical activity and the lowest Cronbach's alpha (0.07) is for the subscale of specific diet

(Table 2).

\section{Construct validity}

The Kaiser-Meyer-Olkin (KMO) value was 0.697 , and the Bartlett's test of sphericity value was $X^{2}=1105.763(d f=136, p<0.001)$. Both KMO and Bartlett's test results indicate that the data had sampling adequacy and could be analyzed using EFA (Dixon, 2013). EFA revealed six factors, namely general diet (4 items), specific diet (2 items), physical activity (2 items), self-monitoring of blood glucose (2 items), foot care (5 items), and medication (2 items) (Table 3). The factor loadings for each item ranged from 0.444 to 0.966 . The cumulative percentage of the total variance in the six factors reached $74 \%$.

\section{Concurrent validity}

Concurrent validity was confirmed because there were significant correlations between three subscales of SDSCA-I and DKQ: general diet $(r=0.274, p=0.002)$, physical activity $(r=0.269, p=0.002)$, and foot care $(r$ $=0.297, p=0.001)$. Furthermore, two subscales of SDSCA-I had significant correlations with HbA1c value: general diet $(r=-0.205, p=$ $0.022)$ and self-monitoring of blood glucose $(r$ $=-0.265, p=0.003)$. 
Table 3. Exploratory factor analysis (EFA) test of the final SDSCA-I

\begin{tabular}{|c|c|c|c|c|c|c|}
\hline Item & $\begin{array}{l}\text { General } \\
\text { diet }\end{array}$ & $\begin{array}{l}\text { Foot } \\
\text { care }\end{array}$ & Medication & SMBG & $\begin{array}{l}\text { Physical } \\
\text { Activity }\end{array}$ & $\begin{array}{c}\text { Specific } \\
\text { diet }\end{array}$ \\
\hline $\begin{array}{l}\text { 1. Followed a healthful } \\
\text { eating plan }\end{array}$ & 0.585 & & & & & \\
\hline $\begin{array}{l}\text { 2. Followed eating } \\
\text { plan }\end{array}$ & 0.519 & & & & & \\
\hline $\begin{array}{l}\text { 3. Eat five or more } \\
\text { servings of fruits } \\
\text { and vegetables? }\end{array}$ & & & & & & 0.444 \\
\hline $\begin{array}{l}\text { 4. Eat high-fat foods, } \\
\text { such as red meat or } \\
\text { full-fat dairy } \\
\text { products? }\end{array}$ & & & & & & 0.828 \\
\hline $\begin{array}{l}\text { 5. Space carbohydrates } \\
\text { evenly through the } \\
\text { day? }\end{array}$ & 0.832 & & & & & \\
\hline $\begin{array}{l}\text { 6. Participate in at } \\
\text { least } 30 \text { min of } \\
\text { physical activity }\end{array}$ & & & & & 0.939 & \\
\hline $\begin{array}{l}\text { 7. Participate in a } \\
\text { specific exercise } \\
\text { session }\end{array}$ & & & & & 0.927 & \\
\hline 8. Test blood sugar & & & & 0.824 & & \\
\hline $\begin{array}{l}\text { 9. Test blood sugar as } \\
\text { recommended }\end{array}$ & & & & 0.811 & & \\
\hline 10. Check your feet & & 0.761 & & & & \\
\hline $\begin{array}{l}\text { 11. Inspect the inside of } \\
\text { shoes }\end{array}$ & & 0.681 & & & & \\
\hline 12. Wash feet properly & & 0.600 & & & & \\
\hline 13. Soaking your feet & & -0.708 & & & & \\
\hline $\begin{array}{l}\text { 14. Dry between toes } \\
\text { after washing }\end{array}$ & & 0.645 & & & & \\
\hline $\begin{array}{l}\text { 15. Take recommended } \\
\text { diabetes medication }\end{array}$ & & & 0.966 & & & \\
\hline 16. Insulin injection & 0.873 & & & & & \\
\hline $\begin{array}{l}\text { 17. Take recommended } \\
\text { number of diabetes } \\
\text { pills }\end{array}$ & & & 0.954 & & & \\
\hline \multicolumn{7}{|l|}{ Initial Eigenvalues: } \\
\hline$\%$ of variance & 16.818 & 15.309 & 11.980 & 11.685 & 10.914 & 7.425 \\
\hline Cumulative $\%$ & 16.818 & 32.127 & 44.107 & 55.793 & 66.707 & 74.131 \\
\hline
\end{tabular}

SDSCA-I: the Summary Diabetes Self-Care Activities Indonesian version; SMBG: SelfMonitoring Blood Glucose 
using a forward and backward approach. The SDSCA-I has satisfactory psychometric properties, as proven through a series of reliability and validity tests. The final version of SDSCA-I has satisfactory internal consistency with Cronbach's alpha of 0.72 . These results are consistent with those for the Malay version (Jalaludin et al., 2012) and the Arabic version (Aljohani et al., 2014).

Three items related to the specific diet subscale (i.e., fruit and vegetable consumption; high-fat food consumption; and spacing carbohydrates throughout the day) had a very low-reliability score. Even though our experts agreed that a specific diet is relevant in the context of diabetes care and is linguistically sound, the participants did not fully understand the meaning of the specific diet. A possible reason is that the specific diet items may not be well understood culturally among Indonesian patients with T2DM. For example, "servings of fruits and vegetables" in Item 3 is ambiguous. It can be referred to fruits and vegetable consumption independently or both are together. In the future, patients with diabetes need to be taught the concepts of diet regimen, specific diet, servings, and spacing carbohydrates.

Another issue is related to the items that required reverse scoring, namely Item 4 ("high-fat food consumption") and Item 13 ("soaking of feet"). Both items need to be reversed before scoring. However, the two items had negative item-total correlations and low internal consistency (Table 2). Similar findings were found for the Spanish version (Vincent et al., 2008) and the Malay version (Jalaludin et al., 2012). To adjust for the low internal consistency, Vincent et al. (2008) suggested that the two items should not be reversed. These items were retained because of the significance of these items on the DM regimen.

The concurrent validity of SDSCA-I was confirmed via its significant association with DKQ. The levels of self-care activity are reflected in the knowledge of T2DM, particularly in the knowledge of general diet, physical activity, and foot care, but the subscales of specific diets, self-monitoring and taking medicine were not associated with the knowledge of T2DM. The non-significant associations may be due to cultural-economic factors, such as the financial burden of buying meat or a blood sugar detector and paternalism in medical adherence. In Indonesia, many patients with diabetes cannot afford to buy a blood sugar detector to perform selfmonitoring. In this study, more than half of the participants had a low level of income $<2$ million Rupiah per month. Paternalism in medical adherence refers to patient follow a physician's recommendation for taking medication without adequate knowledge of diabetes care. The level of diabetes knowledge is associated with diabetes self-care practice (Sharma \& Bhadari, 2017; Sugiharto et al., 2017). Concurrent validity was also demonstrated by the subscales of diet and selfmonitoring being significantly associated with $\mathrm{HbA1c}$ levels. These findings are consistent with previous studies, in which adherence to diet and self-monitoring of blood glucose were significant factors in determining glycemic control (Khattab, Khader, Al-Khawaldeh, \& Ajlouni, 2010). Additionally, frequent selfmonitoring of blood glucose can help T2DM patients adjust their self-care activities (Houle et al., 2015).

The EFA analysis showed that the 17 items of self-care activities are loaded into their relevant factors, which is consistent with the English version of SDSCA, except for Item 5 (spacing carbohydrates) and Item 16 (insulin injection), which are loaded into the general diet factor. Inconsistent factor loading has been reported for the Chinese version of SDSCA, where a diet item was loaded into the subscale of medication (Xu et al., 2008). In the present study, a possible reason is that the term "carbohydrates" is identic with diet and only $3.2 \%$ of the study participants had received insulin injection. The insulin injection performs before the meal time.

Several limitations of this study should be taken into account. First, the study did not 
include patients with type 1 DM (T1DM). Accordingly, the results cannot be generalized to such patients. Future studies should assess the psychometric properties of SDSCA-I for patients with T1DM. The study was conducted in a rural area of Java Island. Since Indonesia has a multi-ethnic population, future investigations in different settings (urban areas, different islands) and with different ethnicities are recommended. Finally, in the present study, the concurrent validity of SDSCA-I was examined using a diabetes knowledge questionnaire and $\mathrm{HbA} 1 \mathrm{c}$ levels instead of any diabetes self-care scales. This is due to the lack of diabetes self-care scales in Indonesia.

\section{CONCLUSIONS}

This study approves that the SDSCA-I is a valid and reliable scale and it has satisfactory psychometric properties. SDSCA-I is a simple tool and requires 5-10 minutes to complete. Thus, SDSCA-I can be used by healthcare providers to assess the self-care activities of patients with T2DM in Indonesia in outpatient departments in hospitals or community settings, and it can be used as a research instrument.

\section{Acknowledgments}

The authors would like to thank all experts for their participation in the crosscultural translation process (Widiantoro, Susri Utami, Saiful Bakhtiar, I Made Sukma Wijaya, Nuniek Nizmah Fajriyah, Nurul Hidayati, Eko Julianto, Sujodo, Retno Tri Probowati, Ferry Susanto, Tri Wahyu Sukarnowati, Titin Hartayu, Esti, and Susan Fetzer).

\section{Conflict of interests statement}

The author(s) declared no potential conflicts of interest with respect to the research, authorship, and/or publication of this article.

\section{REFERENCES}

Adarmouch, L., Sebbani, M., Elyacoubi, A., \& Amine, M. (2016). Psychometric properties of a Moroccan version of the summary of diabetes self-care activities measure. Journal of Diabetes Research, 2016, 1-6. doi:10.1155/2016/5479216.

AlJohani, K. A., Kendall, G. E., \& Snider, P. D. (2014). Psychometric evaluation of the summary of diabetes self-care activitiesArabic (SDSCA-Arabic) translation and analysis process. Journal of Transcultural Nursing, 27(1), 65-72. doi:1043659614526255.

American Association of Diabetes Educators. (2014). AADE7 position statement: AADE7 self-care behaviors. Retrieved from http://www.diabeteseducator.org.

American Diabetes Association [ADA]. (2018). Standards of medical care in diabetes-2018. Diabetes Care, 41 (Suppl. 1): S7-S12. doi:10.2337/dc18-S001.

Beaton, D. E., Bombardier, C., Guillemin, F., \& Ferraz, M. B. (2000). Guidelines for the process of cross-cultural adaptation of self-report measures. Spine, 25(24), 3186-3191. doi: 10.1097/00007632200012150-00014.

Choi, E. J., Nam, M., Kim, S. H., Park, C. G., Toobert, D. J., Yoo, J. S., \& Chu, S. H. (2011). Psychometric properties of a Korean version of the summary of diabetes self-care activities measure. International Journal of Nursing Studies, 48(3), 333-337. doi: 10.1016/j.ijnurstu. 2010.08.007.

Coyle, M. E., Francis, K., \& Chapman, Y. (2013). Self-management activities in diabetes care: A systematic review. Australian Health Review, 37(4), 513522. doi: 10.1071/AH13060

Dal Santo Francisco Bonamichi, B., Caracik de Camargo, L., Ksyvickis dos Louros, M., Bonamichi dos Santos, R., Maria Scalissi A, N., \& Eduardo Nunes Salles, J. (2016). Management of type 2 diabetes mellitus patients and prevalence of complications in a reference center. Integrative Obesity and Diabetes, 2(2). doi:10.15761/iod.1000146.

de Winter, J., Dodou, D.,\& Wieringa, P.A. (2009). Exploratory factor analysis with small sample sizes. Multivariate 
Behavior Research, 44, 147-181. doi: 10.108000027317.

Dixon, JK. (2013). Exploratory Factor Analysis. In Plichta \& Kelvin (6 $6^{\text {th }}$ Eds.), Munro's statistical methods for health care research (pp. 371-398). China: Lippincott Williams \& Wilkins.

Eigenmann, C., Skinner, T., \& Colagiuri, R. (2011). Development and validation of a diabetes knowledge questionnaire. Practical Diabetes International, 28(4), 166-170d. doi: 10.1002/pdi.1586.

Houle, J., Beaulieu, M. D., Chiasson, J. L., Lespérance, F., Côté, J., Strychar, I., ... \& Lambert, J. (2015). Glycaemic control and self-management behaviours in Type 2 diabetes: Results from a 1-year longitudinal cohort study. Diabetic Medicine, 32(9), 1247-1254. doi: 10.1111/dme.12686.

International Diabetes Federation. (2015). IDF Diabetes Atlas (6th Ed.). Retrieved from http://www.idf.org.

Jalaludin, M., Fuziah, M., Hong, J., Adam, B. M., \& Jamaiyah, H. (2012). Reliability and validity of the revised summary of diabetes self-care activities (SDSCA) for Malaysian children and adolescents. EJournal of Malaysian Family Physician, 7(2-3), 10-20. Retrieved from https://www.ncbi.nlm.nih.gov/pmc/artic les/PMC4170432/.

Kamradt, M., Bozorgmehr, K., Krisam, J., Freund, T., Kiel, M., Qreini, M., Ose, D. (2014). Assessing self-management in patients with diabetes mellitus type 2 in Germany: Validation of a Germany version of the summary of diabetes selfcare activities measure (SDSCA-G). Health Quality Life Outcomes, 12(185), 1-10. doi:10.1186/s12955-014-0185-1

Kav, S., Akman, A., Dogan, N., Tarakei, Z., Bulut, Y., \& Hanoglu, Z. (2010). Turkish validity and reliability of the summary of diabetes self-care activities measure for patients with type 2 diabetes mellitus. Journal of Clinical Nursing, 19, 2933-
2935. doi:10.1111/j.1365-2702.2010. 03329.x.

Khattab, M., Khader, Y. S., Al-Khawaldeh, A., \& Ajlouni, K. (2010). Factors associated with poor glycemic control among patients with type 2 diabetes. Journal of Diabetes Complications, 24(2), 84-89. doi:10.1016/j.jdiacomp.2008.12.008.

Kueh, Y. C., Morris, T., \& Ismail, A.-A.-S. (2017). The effect of diabetes knowledge and attitudes on self-management and quality of life among people with type 2 diabetes. Psychology, Health \& Medicine, 22(2), 138-144.

Minet, L., Møller, S., Vach, W., Wagner, L., \& Henriksen, J. E. (2010). Mediating the effect of self-care management intervention in type 2 diabetes: A metaanalysis of 47 randomized controlled trials. Patient Education and Counseling, $\quad 80(1), \quad 29-41$. doi:10.1016/j.pec.2009.09.033.

Mundfrom, D.J., Shaw, D.G., \& Ke, T. L.(2005). Minimum sample size recommendations for conducting factor analyses. International Journal of Testing, 5(2), 159-168.

National Institute of Research and Development of Health. (2013). Riset Kesehatan Dasar 2013. Retrieved from http://www.depkes.go.id.

Polit, D. F., \& Beck, C. T. (2006). The content validity index: are you sure you know what's being reported? Critique and recommendations. Research and Nursing Health, 29(5), 489-497. doi:10.1002/nur.20147.

Ramachandran, A., Snehalatha, C., Shetty, A. S., \& Nanditha, A. (2012). Trends in prevalence of diabetes in Asian countries. World J Diabetes, 3(6), 110117. doi:10.4239/wjd.v3.i6.110.

Sharma, S., \& Bhadari, S. D. (2017). Knowledge and Practice regarding SelfCare among the patients with type II Diabetes of Kapan, Kathmandu. Journal of Advanced Academic Research, 1(2), 85-91. 
Sugiharto, S., Stephenson, M., Hsu, Y.-Y., \& Fajriyah, N. N. (2017). Diabetes selfmanagement education training for community health center nurses in Indonesia: a best practice implementation project. JBI Database of Systematic Reviews and Implementation Reports, 15(9), 2390-2397.

Toobert, D. J., \& Glasgow, R. E. (1994). Assessing diabetes self-management: The Summary of Diabetes Self-Care Activities Questionnaire. In Bradly C. (Ed), Handbook of Psychology \& Diabetes (pp. 351-375). New York: Psychology Press.

Toobert, D. J., Hampson, S. E., \& Glasgow, R. (2000). The summary of diabetes selfcare activities measure: Results from 7 studies and a revised scale. Diabetes Care, 23(7), 943-950. doi: 10.2337/diacare.23.7.943.

Vincent, D., McEwen, M. M., \& Pasvogel, A. (2008). The validity and reliability of a Spanish version of the summary of diabetes self-care activities questionnaire. Nursing Research, 57(2), 101-106. doi: 10.1097/01.NNR.0000313484.18670.ab

Weber, M. B., Oza-Frank, R., Staimez, L. R., Ali, M. K., \& Venkat Narayan, K. (2012). Type 2 diabetes in Asians: prevalence, risk factors, and effectiveness of behavioral intervention at individual and population levels. Annual review of nutrition, 32, 417-439.

World Health Organization. (2016). Diabetes. Retrieved from http://www.who.int/mediacentre/ factsheets/fs $312 / \mathrm{en} /$.

Xu, Y., Savage, C., Toobert, D., Pan, W., \& Whitmer, K. (2008). Adaptation and testing of instruments to measure diabetes self-management in people with type 2 diabetes in mainland China. Journal of Transcultural Nursing, 19(3), 234-242.

doi: $10.1177 / 1043659608319239$. 